\title{
Research Progress of Trace Elements in Gardenia Fructus
}

\author{
Hai-Yan GONG*,Li-Ya Ma, Lin-LinDa,Zhi-Hong Chen, Xiao Luo \\ Henan University of Chinese Medicine, Zhengzhou
}

ghy mz@163.com

\begin{abstract}
Kerwords: Gardenia Fructus; Trace Elements; Research progresss
Abstract.Gardenia Fructus was one of the first batch of edible-medicinal Traditional Chinese Medicine (TCM). Besides chemical composition,its trace elements have been studied extensively.In this paper, the related reports of trace elements in Gardenia Fructus were summarized, which can provide theoretical support for the further development and utilization of Gardenia Fructus.
\end{abstract}

\section{Introduction}

Gardenia Fructus isthe fruit with dry and mature of rubiaceae Gardenia jasminoides Ellis. It has the functions that purging fire and removing vexation, clearing heat, diuresis, cooling blood,detoxification and so on ${ }^{[1]}$.Gardenia Fructus as one of TCM, it belongs to the first batch of edible-medicinal resources which is issued by the ministry of health ${ }^{[2]}$. Its major producing regionsare Jiangxi, Hunan, Zhejiang, Sichuan and other provinces ${ }^{[3]}$.

Trace elements (TE) refers to rarely and even trace in human body.It not only has nutritional role, but can improve the biological activity. At present, it has been confirmed that there are 20 kinds of TE related to human life and health ${ }^{[4]}$. The Gardenia Fructus, gardenia, gardenia leaf, gardenia pigment are rich in TE.And the kinds and contents of TE were diverseinGardenia Fructus from different areas and processing methods. This paper summarize the research progress of TE in Gardenia Fructus from many literatures.

\section{Study on trace elements of Gardenia Fructus}

Gardenia Fructus containsmany kinds of TE. The main kinds of TE,the relationship between the TE and the main chemical componentsin Gardenia Fructusall will be generalized.And the TE in Gardenia Fructus from different areas will be compared.Jianping $\mathrm{Han}^{[5]}$ et al. studied the relationship between 12 kinds of TE and the geniposide. She found that $\mathrm{Mg}$ made the largest contribution to the variation of geniposide, and the content of $\mathrm{Zn}$ was negatively correlated with geniposide.Zhaoxiang Zhou $^{[6]}$ et al. determined the TE in Gardenia Fructus and gardenia pigments, and 20 kinds of TE were found, such as $\mathrm{Cu} \mathrm{Fe} \mathrm{Zn} \mathrm{Mn} \mathrm{Ni}$ Mo V Sb Pb Sn Bi Ca Ag Cd Co Ba Be B Zr Ti. After studying of 14 kinds of TE in Gardenia Fructus from Hunan, Jiangsu, Jiangxiand market,Haiping Liu ${ }^{[7]}$ found that the contents of TE from four areas were close, but the content of $\mathrm{Na}$ was higher in Jiangxi,the content of $\mathrm{Ba}$ was higher in Hunan, and the content of $\mathrm{Cr}$ was the highestincommercially available Gardenia Fructus. Xiaofeng Liao ${ }^{[8]}$ et al. mensurated the TE in water extractof Gardenia Fructus. The resultsshowed that Gardenia Fructus contained a variety of TE, such as $\mathrm{Fe} \mathrm{Zn} \mathrm{Mn} \mathrm{Mg} \mathrm{Cu}$ and so on,in which the content 
of $\mathrm{Mg}$ was the highest. YuncanLi ${ }^{[9]}$ et al.determined the contents of B Co Cr FeMn $\mathrm{Si} \mathrm{Zn} \mathrm{Cu} \mathrm{Se} \mathrm{Ca} \mathrm{Mg}$ $\mathrm{K} \mathrm{Na} \mathrm{p}$, and found that the contents of $\mathrm{K} \mathrm{Ca} \mathrm{Mg}$ Pwere higher.

\section{Study on trace elements in different processed products of Gardenia Fructus}

The efficacy of medicine will be changed after processing according to the clinic needs, which will be more benefit to the treatment of disease. Although the researches on processedproducts of Gardenia Fructus have been started early, they mainly concentrated on the chemical composition, the researches on TE were less.So it is necessary to strengthen the research on TE in different processedproducts of Gardenia Fructus.Shuping $\mathrm{Liu}^{[10]}$ et al.studied 32 kinds of TE in Gardenia Fructus, ginger gardenia, salt gardenia, scorched gardenia, carbonized gardenia and found that the content of TE changed at different levels after processing. The content of TE changed after ginger juice processing.The content ofTE all reduced after salt processing.The content of $\mathrm{Cr}$ had significantly lower after frying, whereas others increased.The contents of $\mathrm{Cr}$ Ti obviously decreasedafter carbonizing, while others increased compared with crude.

\section{Study on trace elements in different parts of Gardenia Fructus}

\section{Study on trace elements in gardenia peel and kernel}

The separated use of gardenia pell and kernel were recorded in "Standards of Diagnosis and Treatment" "Removing the heart hot with gardenia kernel,removing the surface heat with gardenia peel,and removing the upper and middle warmer with the whole Gardenia Fructus,removing the lower warmer clear gardenia pell." The efficacy and the content of TE were diverse in different parts of Gardenia Fructus. Shuping $\mathrm{Liu}^{[10]}$ et al.studied on TE in gardenia peel and kernel,andfound that the TEwasobviously different. All the content of TE in Gardenia peel is greater than the kernel except p.The content of TE in gardenia pell and kernelare different, So itwillbe more benefitto its medicinal function if we use them separately.

\section{Study on trace elements in the exocarp, endocarp and seed of Gardenia Fructus}

Ying $\mathrm{Hu}^{[11]}$ et al.mensurated TE in calyx, exocarp,endocarp and seed of 6 kinds of dry Gardenia Fructus. The results showed that the TE were diverse in different cultivars,and different parts of dried fruits. The exocarp is significantly higher than the endocarp on the TE types and contents. The rare earth element $\mathrm{La}$ and and heavy metals $\mathrm{Ti} \mathrm{Co} \mathrm{W}$ wereonly foundin the seeds. The results further confirmed the scientificity for using each part of Gardenia Fructus separately.

\section{Study on trace elements in different areas of Gardenia Fructus}

The quality of TCMin different origins is diverse, which was affected by the soil, climate, water, minerals distribution. So the active ingredients of TCM from different areasarediverse,the contents of TE also changed. Thereforeit has practical significance to evaluate Gardenia Fructus from different areas from the aspect of TE.Lei Chen ${ }^{[12]}$ et al. measured the contents of FeMn $\mathrm{Ca} \mathrm{Mg} \mathrm{Zn} \mathrm{Cu}$ toassess Gardenia Fructus from 10 different areas. The results showed that there were some different in the content of $\mathrm{TE}$, but the contents of $\mathrm{Ca} \mathrm{Mg} \mathrm{Cu}$ were all higher.Mingdi Liu ${ }^{[13]}$ et al. processed the date from reference [9] for principal component analysis by SPSS13.0 technology.The results showed that the quality of Gardenia Fructus from Henan Tanghewas the best, which had the highest score.

\section{Trace elements in Gardenia Pigment}

Besides medicine, Gardenia Fructus also can beused to extract gardenia pigment.Gardenia pigment is oneof natural pigment.Its advantagesaresafe non-toxic ${ }^{[14]}$ and so on compared with synthetic pigment. The TE in gardenia pigment has a certain influence on its stability.Zhaoxiang Zhou ${ }^{[15]}$ et al. studied on the relationship between $\mathrm{Fe} \mathrm{Cu} \mathrm{Sn} \mathrm{Al}$ and gardenia yellow pigment,and found that $\mathrm{Fe}^{3+}$ can 
make the color ofpigment fade, $\mathrm{Cu}^{2+}$ accelerate the destruction and fading of the pigment, $\mathrm{Sn}^{2+}$ had precipitation phenomenon in gardenia yellow pigment, but $\mathrm{Al}^{3+}$ can improve the stability of gardenia yellow pigment. Qingxin $\mathrm{Zhou}^{[16]}$ found that $\mathrm{Na}^{+} \mathrm{k}^{+} \mathrm{Fe}^{2+} \mathrm{Mg}^{2+} \mathrm{Ca}^{2+} \mathrm{Zn}^{2+}$ had no bad effects on gardenia pigment while the $\mathrm{Fe}^{3+} \mathrm{Cu}^{2+} \mathrm{Al}^{3+} \mathrm{Sn}^{2+}$ can make the gardenia red pigment precipitate, in which the $\mathrm{Fe}^{3+} \mathrm{Al}^{3+}$ had the biggest effect. Donghong You ${ }^{[17]}$ et al.studied the effects of ten metal ions on the stability of gardenia pigment, he found that the effects of $\mathrm{Sn}^{2+} \mathrm{Fe}^{3+}$ were greater. Ruiying Liu ${ }^{[18]}$ studied the effects of metal ionson the stability of gardenia yellow pigment, and found that $\mathrm{Mg}^{2+}$ had less effect, while the effects of $\mathrm{Sn}^{2+} \mathrm{Fe}^{3+}$ were greater.

\section{Determination of heavy metal elements in Gardenia Fructus}

The heavy metal elements in the medicinal materials will cause great harm to the human body, even endanger life. In recent years, the study of heavy metal elements has been paid enough attention, and it has beenviewedas an important link to evaluate the quality of medicinal materials." Green Standards for the Import and Export of Medicinal Plants and Preparations", which was promulgated in 2001, ruled the limit standard for heavy metals: $\mathrm{Pb} \leqq 5.0 \mathrm{mg} \cdot \mathrm{kg}^{-1} \mathrm{Cd} \leqq 0.3 \mathrm{mg} \cdot \mathrm{kg}^{-1} \mathrm{As} \leqq 2.0 \mathrm{mg} \cdot \mathrm{kg}^{-1}$ $\mathrm{Hg} \leqq 0.2 \mathrm{mg} \cdot \mathrm{kg}^{-1}$. Chen $\mathrm{Lei}^{[19]}$ et al. determined the contents of $\mathrm{Pb} \mathrm{Cd}$ As in Gardenia Fructus from different regions by graphite furnace atomic absorption spectrometry.Hydride-cold atomic absorption method was used to measure $\mathrm{Hg}$.All samples meet the above criterias. Shu Zhou ${ }^{[20]}$ and $\mathrm{Yi} \mathrm{Liu}^{[21]}$ determined heavy metals inGardenia Fructus, the results were also meet the limit standard.

\section{Trace elements in other parts of gardenia}

\section{Gardenia}

Besides highly ornamental value, gardeniaalso can be used for health food, even medicine ${ }^{[22]}$.Gardenia healthcare effect has oftenbeen overlooked, and the study found that the contents of TE in gardeniawere more abundant than the Gardenia Fructus, which provided theoretical support for the development and utilization of gardenia. Jiajian Zhang ${ }^{[2]}$ et al. mensurated the contents of $\mathrm{Ca} \mathrm{Zn}$ $\mathrm{Cu} \mathrm{Mn} \mathrm{Cr} \mathrm{Mg} \mathrm{Fe} \mathrm{in} \mathrm{the} \mathrm{gardenia} \mathrm{and} \mathrm{Gardenia} \mathrm{Fructus,the} \mathrm{results} \mathrm{showed} \mathrm{that} \mathrm{the} \mathrm{contents} \mathrm{of} \mathrm{TE} \mathrm{in}$ gardenia were higher. Kaiquan $\mathrm{Li}^{[23]}$ et al.determined 13 kinds of TE in gardenia, the data showed that the content of TEwere as follows: $\mathrm{Cu}>\mathrm{Ca}>\mathrm{P}>\mathrm{Mg}>\mathrm{K}>\mathrm{Fe}, \mathrm{Mo}>\mathrm{Co}>\mathrm{Na}>\mathrm{Se}>\mathrm{Zn}>\mathrm{Mn}>\mathrm{Ge}$.

\section{Gardenia Pollen}

Gardenia pollen is rich in nutrients, which can be used as trophic food for disease prevention and treatment ${ }^{[24]}$.Besides nutrients,Meizhu Chen ${ }^{[24]}$ et al.measured thecontents of $\mathrm{K} \mathrm{Na} \mathrm{Mn} \mathrm{Ca} \mathrm{Mg} \mathrm{Fe} \mathrm{Cu} \mathrm{Zn}$ $\mathrm{Se}$ in yellow gardenia pollen. The results showed that the contents of TE were rich in gardenia pollen, and $\mathrm{Fe}, \mathrm{Zn}$ were higher.

\section{Gardenia Leaf}

Gardenia leaf is notused for medicinal purposes, but itsTE is helpful to estimate the effective components of Gardenia Fructus. FangLiu ${ }^{[25,26]}$ et al. mensuratedthe contents of $\mathrm{Fe} \mathrm{Mn} \mathrm{Zn} \mathrm{Se}$ in gardenia leaves to calculate the main effective constituents of Gardenia Fructus by establishing mathematical model. 


\section{The determination method of trace element}

There are many methods for testingthe TE with the advance of the research,the testing equipment is more advanced.It provides a strong technical support for scientific research. In order to measure the TE conveniently, it is necessary to convert the metal compounds into ionic state firstly.

\section{The sample preparation}

The frequently-used sample pretreatment includes high-pressure sealed digestion method (pressure digestion tank digestion method), dry ashing and wet digestion ${ }^{[27]}$.Yuncan $\mathrm{Li}^{[9]} \mathrm{et}$ al. pretreated Gardenia Fructus by microwave digestion.Lei $\mathrm{Chen}^{[12]} \mathrm{et}$ al. further studied the different digestion methods of $\mathrm{HNO}_{3}+\mathrm{HCl}, \mathrm{HNO}_{3}+\mathrm{H}_{2} \mathrm{O}_{2}, \mathrm{HNO}_{3}+\mathrm{HClO}_{4}, \mathrm{HNO}_{3}+\mathrm{HF}$, who found that the method of $\mathrm{HNO}_{3}+\mathrm{H}_{2} \mathrm{O}_{2}$ digested completely, solution clarification, and stimulating and corrosive was low, so the digestion method of $\mathrm{HNO}_{3}+\mathrm{H}_{2} \mathrm{O}_{2}$ was the best.

\section{Determination analysis method}

\section{Atomic Absorption Spectrometry}

Atomic absorption spectrometry (AAS) is divided into flame atomic absorption spectrometry (FAAS) and graphite furnace atomic absorption spectrometry (GFAAS), cold atomic absorption spectrometry (CAAS), Hydride generation atomic absorption spectrometry (HGAAS) ${ }^{[28]}$. The FAAS can determine more kinds of elements, but thesensitivity of GFAAS ismore higher. Xiaofeng Liao ${ }^{[8]} \mathrm{et}$ al. mensurated TE in gardenia extract by AAS.Lei Chen ${ }^{[9]}$ et al.determined TE in Gardenia Fructusfrom different areas by FAAS. Jiajian Zhang ${ }^{[22]}$ et al. used AAS to determine TE in gardenia and raw Gardenia Fructus.Kaiquan $\mathrm{Li}^{[23]}$ et al.determined $\mathrm{FeMn} \mathrm{Zn} \mathrm{Cu}$ Mo $\mathrm{Ca} \mathrm{Mg} \mathrm{K} \mathrm{Na}$ by FAAS, and determined Mo Co Ge Se by GFAAS. Fang Liu ${ }^{[25,26]}$ et al. mensurated the contents of Fe Mn Zn Se in gardenia leaves by FAAS.

\section{Atomic Emission Spectrometry}

Atomic emission spectrometry (AES) is an analysis method which is according to the characteristic spectral lines.The lines are emitedby theatom of elementswhichare measured from the excited state to the ground state.MeizhuChen ${ }^{[24]}$ et al. used this method to determinethe content of TE in gardenia pollen.

\section{Colorimetry}

Colorimetric method has the advantages of simple equipment and convenient operation,but the accuracy is not high enough. Kaiquan $\mathrm{Li}^{[23]}$ et al.determined the content of $\mathrm{P}$ in gardenia bycolorimetric method.

\section{Atomic Fluorescence Spectrometry}

Atomic fluorescence spectrometry (AFS) is a method that the ground state atomic is emitted to the upper state after it absorb specific frequency radiation,then it launch characteristic wavelength fluorescence in the form of ray radition. This method has high sensitivity.YingHu ${ }^{[11]}$ et al.mensuratedthe TE in each parts of dried Gardenia Fructus by AFS.

\section{Ultraviolet Spectrophotometry}

Ultraviolet spectrophotometry (US) is a method for determining the contents of metal elements. It has a color and absorption phenomenonin the ultraviolet lamp after the reaction of the metal element with the specific reagent.Zhaoxiang Zhou ${ }^{[15]}$ et al.used US for the determination of TE in gardenia pigment. 


\section{Inductively Coupled Plasma Atomic Emission Spectrometry}

Inductively coupled plasma atomic emission spectrometry (ICP-AES) is a spectral analysis method, which is based on inductively coupled plasma as excitation source. It has the advantages of high accuracy, high precision, low detection limit, rapid determination,wide linear range, simultaneous determination of various elements and so on.Jianping $\mathrm{Han}^{[5]}$ et al.and Yuncan $\mathrm{Li}^{[9]}$ et al.mersuredthe TE in Gardenia Fructus by ICP-AES.Shuping $\mathrm{Liu}^{[10]}$ et al.also used ICP-AES in the test of TE in different processed products. The method is simple and reliable.

\section{Inductively Coupled Plasma Mass Spectrometry}

Inductively Coupled Plasma Mass Spectrometry ( ICP-MS) is a highly sensitive analytical technique with unique interface technology. which combines the advantages of the high temperature ionization characteristics of ICP and the sensitive and rapid scanning ofMS.Haiping Liu ${ }^{[7]}$ determined TE in Gardenia Fructus by ICP-MS.

\section{Research prospect}

Gardenia Fructus has abundant TE. At present, 37 kinds of TE in Gardenia Fructuswere determined. Based on the current literature, though the study of Gardenia Fructus is extensive, there are still many deficiencies and gaps. $\AA$ The chemical components and the pharmacological effects of Gardenia Fructus were different in diverse harvest times ${ }^{[29]}$, the content ofTE may also be different,so the study of TE can be used asanauxiliary judgment of Gardenia Fructus`s best harvest time. Ç The correlation betweenTE and pharmacological action of Gardenia Fructus can also be studied. É The current researchesonTEare Gardenia Fructus, Gardenia, Gardenia leaf, there is no correlativereport of TE in gardenia root though it can also be used as medicine.Researching on it can provide scientific basis for the further development and utilization of Gardenia roots. (4)Moreover, the present researchesare mainly concentrated on the mountain Gardenia Fructus, water Gardenia Fructus are less. It is controversial that whether it can be used as medicine. So the determination of TE may help judge its medicinal value. It will be more conducive to the use of Gardenia Fructus if we accelerate the relevant research,which can provide more support for people's lives and health.

\section{Acknowledgements}

This work was financially supported by the Henan college of traditional Chinese medicine nursery engineering projects(MP2013-32).

\section{References}

[1] National pharmacopoeia committee of the People's Republic of China,Pharmacopoeia of the People's Republic of China (2015, part I ), China Medical Science and Technology Press, Beijing,2015, pp.248.

[2] F.S. Liao, Research Development of Gargenia,Guangzhou Chem Ind.01(2013)12-13+21.

[3] M.P. Lv, L. Zhou, J. Yan, Y.Q. Wang, Determination of Geniposide in Gardenia Fructus from different habitats,Chin. J. Chin. Mater. Med.10(2002)68-69.

[4] Z.M. Huang, X. Huang, Trace Elements and Human Helth,Studies. Trace Elements\& 
Health.06(2010)58-62.

[5]J.P. Han, Y.Y. Wang, W.S. Zhang, Y.L. Zhang, L.H.Zhao,Study on the Relationship Between Microelement,PH and the Conent of Gentiobioside in Gardenia jasminoides, Life Sci. Res.02 (2006) 134-138.

[6]Z.X. Zhou, J.W. Chen, An analysis of trace elements in the fruit and xanthophyl of Gradenia jasminoides Ellis,J.Zhejiang Forestry College.03(1988)46-51.

[7]H.P. Liu,Study on chemical constituents and quality of Gardenia Fructus, D. Capital Normal Univ. (2007).

[8] X.F. Liao, Z.X. Chen, R. Yu, Y.Z. Li, Analysis of trace elements in the extract of Gardenia Fructus, Sci. Technol. Food Ind. 12(2005)177-179+59.

[9]Y.C. Li,H. Fu, N. Zhao, R. Lei, Determination on Trace Elements in Gardenia by Microwave Digestion -ICP-AES, J.Anhui Agri. Sci.22(2010)11787-11788.

[10]S.P. Liu, R.N. Yan, D.Z. Cai, Auantitative Analysis of Trace elements in Zhizi with Different Process methods, Studies. Trace Elements\& Health.02(1997)23-24.

[11]Y. Hu, M.H. Wu,J.J. Xie, L.Li,Quantitative analysis of elements in different parts of dried Gardenia fruits, Studies. Trace Elements\& Health.02 (2008)24-27.

[12]L. Chen,Y. Liu,Determination of Content of Microelements in Gardenia Fructus with the Method of FAAS, Chin. J. Exp. Tradit. Med. Form.03(2012)90-92.

[13]M.D. Liu,Z.X. Qi,D. Ye,Principal Component Analysis of Trace Elements in Gardenia From Different Regions, J.Sichuan Univ. Sci\& Eng (Nat. Sci. Ed). 02(2014)15-18.

[14] X.J. Tang, L.H. Lu, Advance on Gardenia Pigment Study, Food Sci.12(2005)254-256.

[15]Z.X. Zhou, Y. Zhu,G.B. Li, Y.F. Luo,Reactions Between Xanthophyll from Gardenia Jasminoides Ellis and Metallic Ions,Chem. Ind. Forest Products.03(1988)50-57.

[16]Q.X. Zhou,Developmentand Researchof Gardenia Pigments, D.Fujian Agriculture and Forestry Univ.(2011).

[17]D.H. You, Y.Y. Zheng, Extraction of Yellow Pigment from Gardenia Hasminoides and Its Stability, J.Quanzhou NormalUniv.06(2001)47-49+74.

[18]R.Y. Liu,Research on Comprehensive Extraction Technology of Compositions in Gardenia and Stability of Pigment, D.Zhengzhou Univ.(2009).

[19]L. Chen,Y. Liu,Determination of Heavy Metal Elements in Gardenia Fructus from Different Habitats, Chin. J. Exp. Tradit. Med. Form.23(2011)68-70.

[20] S. Zhou, Studies on the quality of fructus gardeniae fruits from GAP base, D. Guangzhou Univ. Chin. Med.(2010).

[21] Y. Liu, Research on the Quality Evaluation Method of "zhizi”, D. Henan Univ. Chin. Med.(2010).

[22]J.J. Zhang,D. Shou,J.M. Zhang,Z.M. Yu,Analysis and Research on the medicinal value of Gardenia,Zhejiang J. Tradit. Chin. Med.07(2008)424-425. 
[23]K.Q. Li,X.M. Zeng,H.L. Tao,Determination of vitamins and trace elements in the Gardenia, Jiangxi J. Tradit. Chin. Med.05(2012)64-66.

[24]M.Z. Chen,X.C. Zhang,W.J. Chen,P.J. Hong, Study on Nutrient Comosition of Pollen of Gradenia Jasminoides Ellis,J. Liaocheng Univ. (Nat. Sci. ). 01 (2001)77-78+89.

[25]F. Liu,C. Tang,H.F. Zheng,Y. Zhou,Z.H. Huang,L.B. Jiang,Y. Huang,Study on the pattern of quantitative changes between the main effective components and microelements in Fructus Gardenia, Chin. J. Pharm. Anal.05(2015)893-899.

[26]F. Liu, the Impact on Gardenia quality about the microelements in Leaf soil and irrigation water the PH and the climate, D.Sichuan Med. Univ.(2015).

[27]M.H. Yang, J.W. Wu,R.H. Zhao, Research Progress on detection and removal of heavy metals in Chinese herbal medicines, Modern Chin. Med.01(2008)3-7.

[28] L. Yang, X.Y. Dong, D.Y. Meng, The common determination method of trace elements in coal, Chin. Min. Mag. S2(2014)293-300.

[29]Z.W. Wang,C. Tang, J.J. Sun,G. Wang,R. Huang,X. Li, Multi-index comprehensive evaluation on the reasonable harvesting and growing period of Fructus Gardenia in Bazhong,Chin. J. Pharm. Anal. 09(2012)1554-1558+1563. 